\title{
ESTUDO GEOHISTÓRICO SOBRE A DISTRIBUIÇÃO DOS SERVIÇOS NA AVENIDA PRESIDENTE BANDEIRA NO BAIRRO DO ALECRIM EM NATAL/RN
}

\author{
WELLITON BELO DA ROCHA \\ GERSON GOMES DO NASCIMENTO
}

Instituto Federal de Educação, Ciência e Tecnologia do Rio Grande do Norte.

\section{Resumo}

O presente trabalho analisa o setor de serviços na Avenida Presidente Bandeira no bairro do Alecrim em Natal/RN. O estudo parte da análise de que esse processo está associado ao processo de produção e reprodução urbana na ótica capitalista evidenciando a ação dos agentes no processo que aí atuam resultando em diferenciações dessas atuações no espaço que o torna desigual. Apresenta a evolução histórica do conceito de serviços (suas correntes) evidenciando-o como o setor econômico que mais tem crescido na economia do Rio Grande do Norte, sobretudo na cidade de Natal. O trabalho procura mostrar os tipos de serviços existentes bem como classificá-los dentro do contexto da produção do espaço e suas vertentes e que estão presentes nessa avenida. Enquanto procedimentos metodológicos o trabalho constitui-se de pesquisa bibliográfica buscando dialogar com os principais teóricos relacionados ao estudo em tela e complementado por uma pesquisa de campo onde buscamos corroborar os estudos por meio dos fatos empíricos constatados na visita ao campo de estudo do presente trabalho. Concluímos que o estudo nos leva a afirmar que a referida Avenida Presidente Bandeira se constitui como uma das principais artérias viárias do bairro do Alecrim e como tal é geradora de emprego notadamente no comércio e serviços.

Palavras-Chaves:Produção e Reprodução do Espaço. Serviços. Avenida Presidente Bandeira.

\section{Abstract}

This paper analyzes the services sector at Presidente Bandeira Avenue in Alecrim neighborhood in Natal / RN. The study of the analysis that this process is associated with the production and reproduction process in urban capitalist perspective showing the action of the agents in the process working there resulting in differences of these actions in space that makes it uneven. It presents the historical evolution of the concept of services (their current) showing it as the economic sector that has grown the most in the Rio Grande do Norte economy, especially in Natal. The work aims to show the types of services and classify them within the context of the production of space and its dimensions and that are present in this avenue. While methodological procedures work consists of literature seeking dialogue with the main theoretical related to study screen and supplemented by field research where we seek to corroborate the studies by the empirical facts noted in the visit to the field of study of this work. We conclude that the study leads to claiming that that President Bandeira Avenue constitutes the one of the main road arteries of the Alecrim neighborhood and as such generates a large flow of the third sector of the economy especially in trade and services.

Keywords: Production and Space Playback. Services.

Presidente Bandeira Avenue. 


\section{Introdução}

O setor de serviços é atualmente o que mais cresce dentro do cenário atual da economia quer seja a nível mundial ou local. No estado do Rio Grande o setor terciário representa $74,3 \%$ do Produto Interno Bruto-PIB potiguar destacando-se nas áreas de gastos públicos e do comércio segundo o Perfil Econômico do Rio Grande do Norte (2014, p. 74). Apesar do redirecionamento das atividades comerciais para outras áreas da cidade, o setor comercial ainda é muito marcante no bairro do Alecrim na Zona Leste da cidade Natal (PERFIL ECONÔMICO DO RIO GRANDE DO NORTE, 2014, p. 74).

0 presente trabalho pretende, pois, analisar a distribuição dos serviços na Avenida Presidente Bandeira no bairro do Alecrim, Natal-RN. A pesquisa surgiu pela necessidade de se compreender como se deu o processo de organização socioespacial e sua distribuição no referido bairro através do tempo, sobretudo a partir da criação deste até os dias atuais. Nesse sentido a pesquisa buscou por meio da investigação bibliográfica e de campo estudar esse processo de formação das atividades relacionadas ao setor terciário do bairro do Alecrim, destacando a supracitada avenida como área de estudo.

Para tanto nos baseamos nos referenciais bibliográficos tais como Santos $(2001,2006$, 2008, 2012), Lefebvre (2008) e Harvey, (1980) a quem recorremos para analisar a formação do espaço habitado; Cascudo e outros que nos ajudaram a investigar a origem histórica do bairro do Alecrim e pôr fim a pesquisa de doutoramento do professor Nascimento (2012) que nos ajudou a compreender as atividades do setor de serviços na atualidade no tocante à cidade de Natal.

Assim, os seguintes objetivos permearam o estudo que ora apresentamos:

Analisar o processo de produção/reprodução urbana do bairro do Alecrim;

Evidenciar a importância do terceiro setor da economia na Avenida Presidente Bandeira;

Mostrar a atual distribuição dos serviços na área objeto de estudo.

Para alcançar tais objetivos, recorremos, além da pesquisa bibliográfica recorremos à pesquisa de campo a qual foi de fundamental importância. Para isso visitamos o bairro e a referida avenida enquanto recorte socioespacial de nossa área de pesquisa bem como entrevistamos os comerciantes ali estabelecidos.

Assim, acreditamos que esse trabalho se justifica em função da necessidade de se compreender o setor terciário no bairro do Alecrim, bairro esse tradicionalmente relacionado com as atividades comerciais, notadamente na área objeto de estudo enquanto maior atividade terciária popular na capital potiguar na atualidade. 


\section{CARACTERIZANDO A ÁREA DE ESTUDO}

O Alecrim é um bairro situado na Região Administrativa Leste da cidade de Natal capital do Rio Grande do Norte. Em ordem de criação é o quarto bairro criado em Natal . É o bairro que concentra o setor de comércio popular da capital potiguar razão pela qual é um dos bairros mais populosos atraindo não só os moradores da capital como também do interior do estado bem como de outros estados da região.

\section{A origem do bairro do Alecrim}

O bairro do Alecrim teve seus primeiros moradores se fixando no local na última década do século XIX, já com suas avenidas e ruas numeradas, é uma réplica da Cidade Nova (GALVÃO 2007, p.21). O desenvolvimento do lugar a partir do segundo decênio do século XX permitiu assim o avanço demográfico e urbanístico de Natal em direção aos tabuleiros. Em 1909 o bairro ainda estava em formação. O bairro do Alecrim foi oficialmente criado através do Decreto da Intendência Municipal de Natal, datado de 23 de outubro de 1911 oficializado em 30 de setembro de 1947, na administração do Prefeito Silvio Piza Pedroza (JÚNIOR, 2007, p.130). Em 1941-1942 Natal tinha 200 logradouros públicos sendo 35 deles situados no Alecrim, dos quais 2 avenidas, 2 praças, 28 ruas e 3 travessas (GALVÃO, 2007, p.24).

Sobre a origem toponímica do bairro do Alecrim sabemos que (DANTAS 2007, p. 84):

Conservou sua primitiva denominação poética em homenagem ao monumento dessa "cotovia mística das rimas" que pelos séculos adiante jamais perderá a força embriagadora do seu lirismo divino, no horto de arminho, onde as almas dos humildes e dos simples vêm aprender com ela a sonhar, com essa que o poeta viu dormindo eternamente entre lilases, boiando na corrente das mágoas como um lótus de extintas primaveras.

Apesar da conotação poética para o surgimento do nome do bairro, a realidade era bem outra. No início do surgimento do Alecrim, o local não passava de um arrabalde de pessoas pobres. Já para Cascudo (2007, p. 101), no bairro estendiam-se ruas claras e alegres, povoadas e álacres. A figura 1 mostra aspectos do bairro do Alecrim na década de 1960.

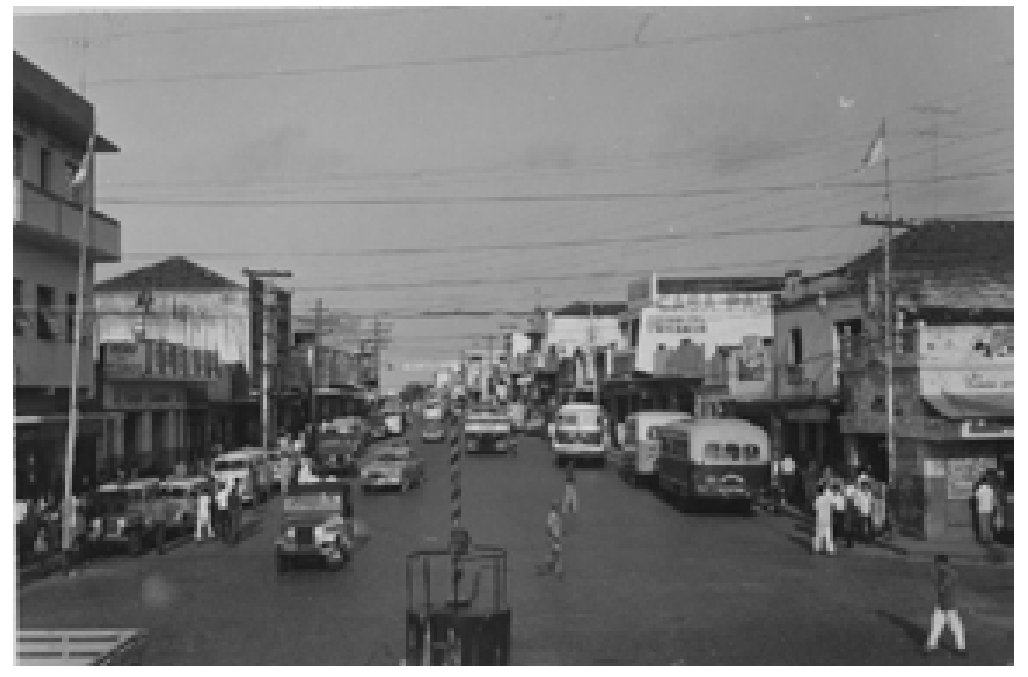

Figura 1- Imagem do bairro do Alecrim

Fonte: http://www.omb100.com/ natal-alecrim/historia. Acesso em 06 junho. 2016. 
Destaca-se como símbolos históricos do bairro Alecrim o primeiro cemitério público de Natal, o Alecrim Futebol Clube e a igreja de São Pedro. No bairro também foi criado um dos mais antigos grupos de escoteiros de Natal, a Associação dos Escoteiros do Alecrim fundado em 24/06/1917 onde a sede do referido grupo se localiza no atual Instituto Padre Miguelinho . Na década de 1940 foi construído um dos dois mercados públicos de Natal à época, o outro estava situado na Cidade Alta (CÂMARA, 2007, p.108) e nesse período o bairro do Alecrim se firmaria como bairro comercial de Natal. Destacamos ainda a sede do $3^{\circ}$ Distrito Naval da Marinha.

Como dito anteriormente, o bairro do Alecrim estava constituído de 18 avenidas numeradas, no entanto, não nos foi possível identificar os nomes correspondentes as avenidas numeradas de 13 a 18, uma vez que tal numeração se deve ao fato das pessoas do bairro deixar de usar o costume de numeração das avenidas adotando o nome civil, assim, no bairro do Alecrim coexistem as duas formas de se referir as avenidas, até mesmo nas que são tradicionalmente conhecidas pela numeração a exemplo da avenida em estudo, a avenida 2. Assim, as pessoas do lugar se referem a ela tanto pelo número como pelo nome oficial que é Avenida Presidente Bandeira.

As pessoas mais antigas do bairro acreditam que a numeração das avenidas foi criação dos americanos durante sua permanência na capital potiguar na Segunda Guerra Mundial, no entanto constatamos que o sistema de numeração é bem anterior a chegada dos americanos a Natal como já mencionado anteriormente. Com relação à Avenida Presidente Bandeira ou Avenida 2 no bairro do Alecrim a mesma faz homenagem a João Capistrano Bandeira de Melo que governou o Rio Grande do Norte no período de 1873 a 1875 (JUNIOR, 2007, p. 131). A figura 2 mostra a Avenida 2 ou Presidente Bandeira no Alecrim nas décadas de 1950 e 1960.

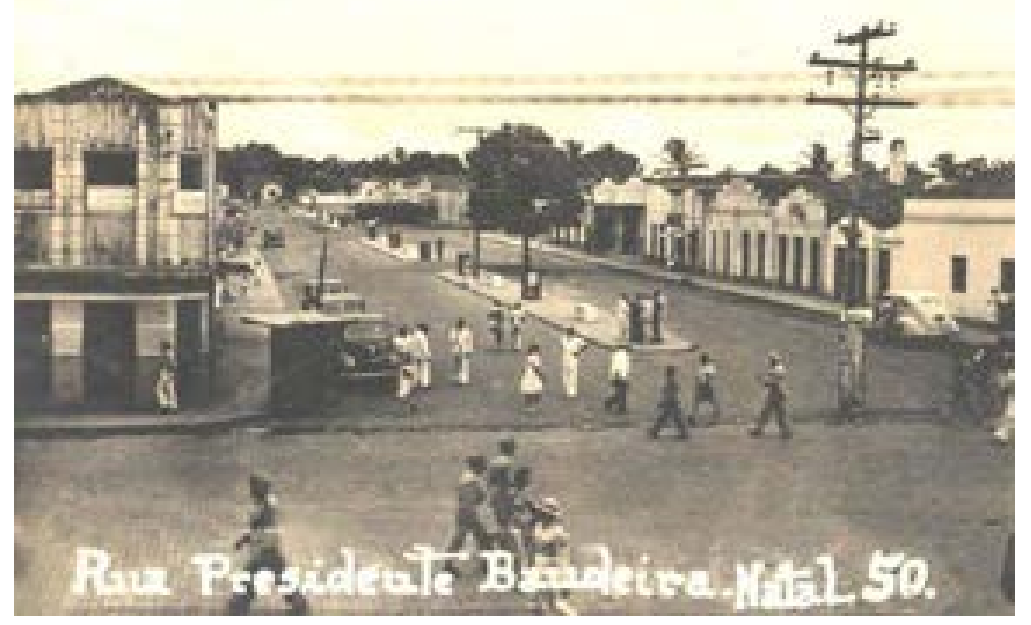

Figura 2- Avenida Presidente Bandeira no Alecrim

Fonte: http://cafehistoria.ning. $\mathrm{com} / \mathrm{profiles} / \mathrm{blogs} /$ alecrimalgumas-considera. Acesso 06 jun. 2016.

Pelas imagens podemos observar a evolução urbana da referida avenida num período de 10 anos sendo o comércio responsável por tais transformações no local. Essa avenida sempre manteve essa característica relevante no que se refere à sua organização socioespacial direcionada aos serviços (JÚNIOR, 2007). 


\section{Localização Geográfica e a Distribuição dos Serviços na Avenida Presidente Bandeira}

O bairro do Alecrim está situado na região administrativa leste da cidade do Natal capital do Rio Grande do Norte. 0 mapa 1 mostra a localização bairro do Alecrim no mapa da cidade de Natal em destaque. Neste mapa é possível identificar a posição do bairro do Alecrim em relação aos demais bairros da cidade de Natal, já o mapa 2 mostra a delimitação do bairro do Alecrim.

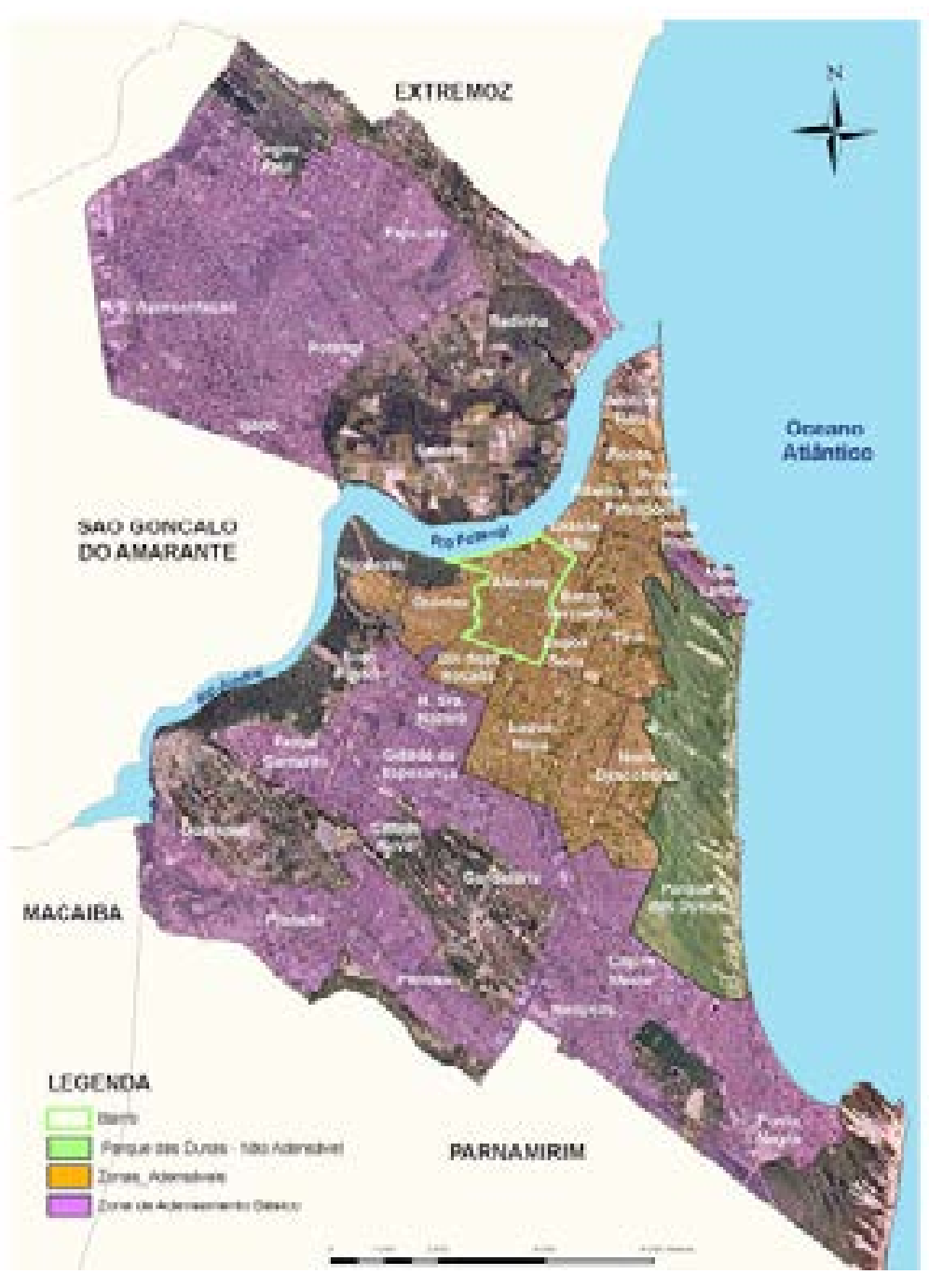

Mapa 1- Mapa da cidade de Natal.

Fonte: SEMURB, 2016. 


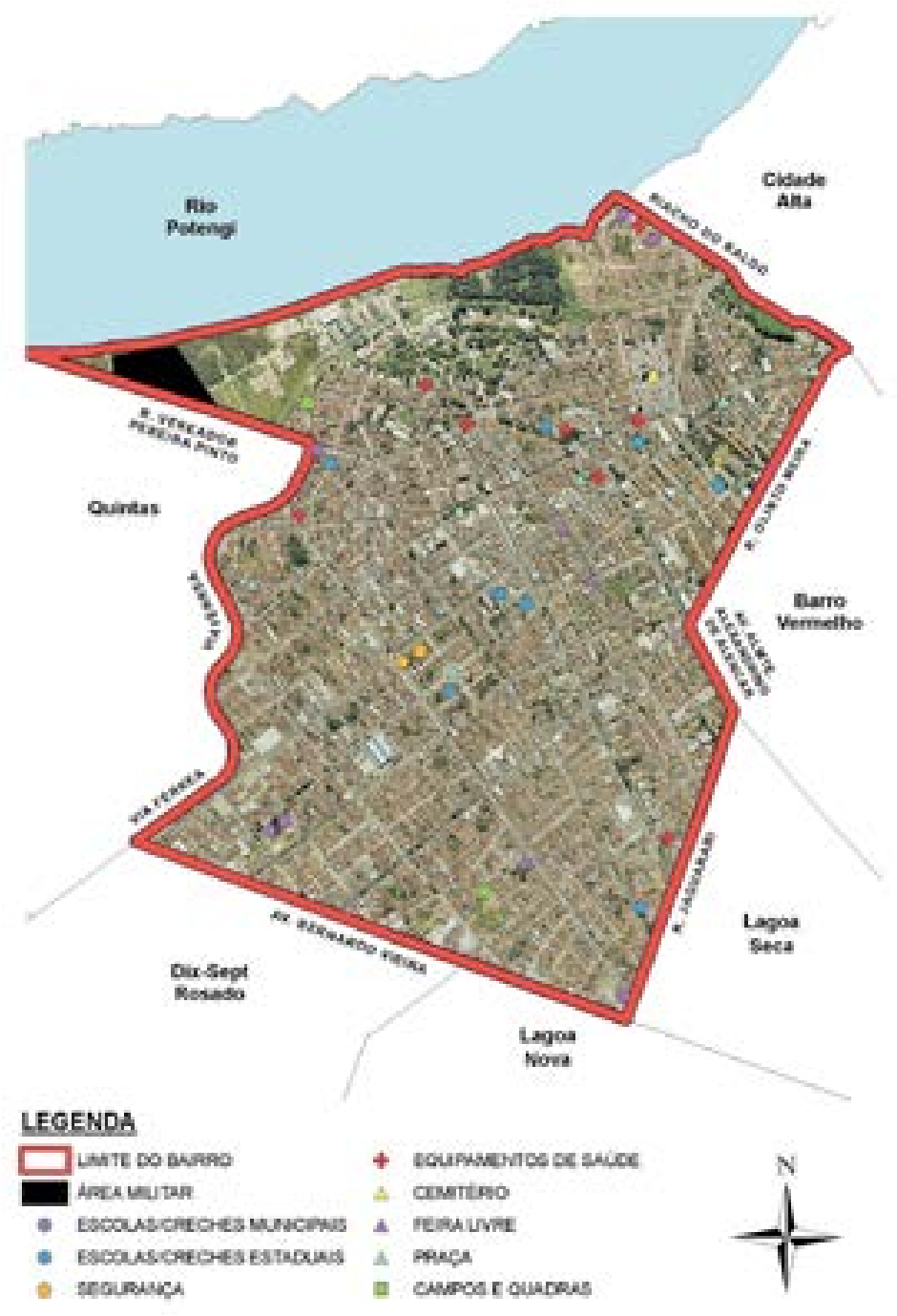

Mapa 2- Delimitação do bairro do Alecrim

Fonte: SEMURB, 2008.

Assim, observamos que o bairro do Alecrim se limita ao Norte com Rio Potengi e Cidade Alta; ao Sul com Lagoa Nova e Dix-Sept Rosado; a Leste com Barro Vermelho e Lagoa Seca e a Oeste com as Quintas, possuindo 309,37 de hectares de área e população estimada em 94.347 segundo dados do Censo 2010 do IBGE ficando em $9^{\circ}$ lugar entre os 10 bairros mais populosos de Natal (IBGE, 2010). O Alecrim é o tradicional bairro comercial de Natal, tendo no comércio de rua sua principal força impulsionadora da renda gerada no comércio e serviços ali existentes. Segundo Nascimento (2007, p.23), o setor terciário do bairro do Alecrim mostrava-se bem consolidado e diversificado já na década de 1970. Considerando a produção de territórios pelo setor terciário, o autor (2007, p. 25) afirma que tais territórios são intermediados formas de consumo diversas das quais fazem parte os meios de transportes, hospedagens, ramos de atividades alimentícias, têxteis, calçados, bancos e escolas. Estas atividades é que dão a tônica do funcionamento desses territórios.

Percebemos que na avenida em questão além do camelódromo, que é um "território próprio" da Avenida Presidente Bandeira, não há uma uniformidade na distribuição dos estabelecimentos comerciais, como há em outros pontos do próprio bairro do Alecrim, como por exemplo, as avenidas onde existe a concentração de óticas e outras de lojas de produtos automotivos. Na avenida há uma heterogeneidade em relação à distribuição dos estabelecimentos comerciais e de serviços. 
Segundo Holanda, em 2011 o bairro empregava 35 mil pessoas no comércio com carteira assinada, representava $74,44 \%$ do comércio varejista, sendo $40 \%$ dos estabelecimentos comerciais e contribuindo com $35 \%$ do ICMS de Natal. 0 varejo é a explicação natural para a vocação comercial do Alecrim segundo Holanda (HOLANDA, 2015, P. 77). A feira do Alecrim localizada na Avenida Presidente Quaresma e adjacências é o grande atrativo do bairro sendo realizada tradicionalmente aos sábados. Existindo desde 20 de junho de 1920, é realizada num espaço de $515 \mathrm{~m}^{2}$ de cobertura (tendas), com 1.056 bancas, banheiros, lixeiras e placas de identificação de produtos que estão separados por tipos de produtos (HTTP://WWW.COMPRENOALECRIM.COM.BR). A feira do Alecrim é a maior e mais tradicional feira da capital potiguar.

Há no Alecrim uma extensa rede de avenidas, como a Coronel Estevam, a Amaro Barreto, a Presidente Quarema, a Avenida Alexandrino de Alencar e a própria Presidente Bandeira que se articula com as demais regiões de Natal sendo estas as principais vias de articulação do bairro com o restante da cidade. Há ainda a presença dos mais variados tipos de serviços e comércio no referido bairro de tal forma que algumas ruas chegam a ter um só seguimento de comércio ou serviço com empresas de pequeno e médio porte.

Outro destaque na economia do bairro do Alecrim é a sua economia Informal que "se tornou um grande atrativo no bairro, tendo este proporcionado grandes transformações socioespaciais no mesmo, algumas não muito desejadas" (NASCIMENTO, 2011, p. 81). A figura 3 mostra aspectos da Avenida Presidente Bandeira na altura do camelódromo.

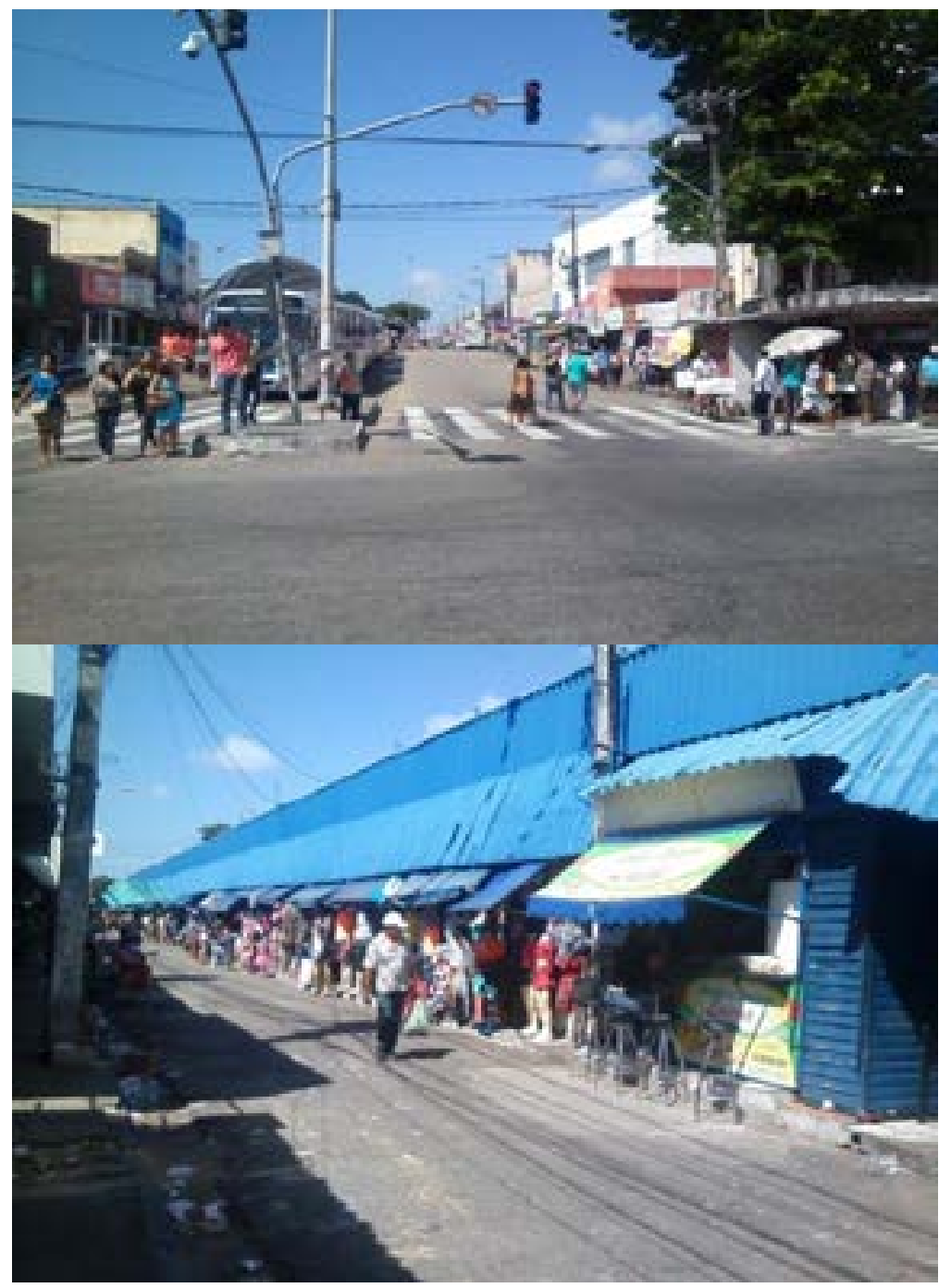

Figura 3. Avenida Presidente Bandeira na altura do camelódromo. Fonte: acervo do autor, 2016. 
As imagens mostram início do camelódromo, à esquerda no lado destinado somente ao fluxo de pedestre e o cruzamento com a avenida Cel. Estevam, à direita; nestes locais se percebe a grande quantidade de comerciantes informais na avenida em estudo. Os locais retratados nas imagens são pontos de grande concentração de pessoas e fluxo de trânsito devido ser cruzamento com uma das principais avenidas do bairro, a avenida Cel. Estevam.

Assim, é notório que numa simples ida ao bairro do se perceba o caos nas ruas, a movimentação dos carros e transeuntes, o barulho, a poluição sonora e visual, a falta de estacionamentos, a presença de ambulantes e camelôs competindo com os lojistas pela atenção dos consumidores bem como as pessoas que se "acotovelando" pelas suas principais ruas e avenidas a exemplo da área de estudo em questão.

Nesse sentido, acreditamos que o crescimento desordenado aliado a falta de atenção aos problemas estruturais do bairro por parte do poder público e a falta de qualificação e gestão por parte de proprietários de estabelecimentos comerciais são os grandes problemas estruturais do Alecrim na atualidade. Apesar disso, o bairro ainda se apresenta como o maior e mais importante centro de comercio popular de Natal. A figura 4 mostra aspectos da Avenida Presidente Bandeira no seu início.

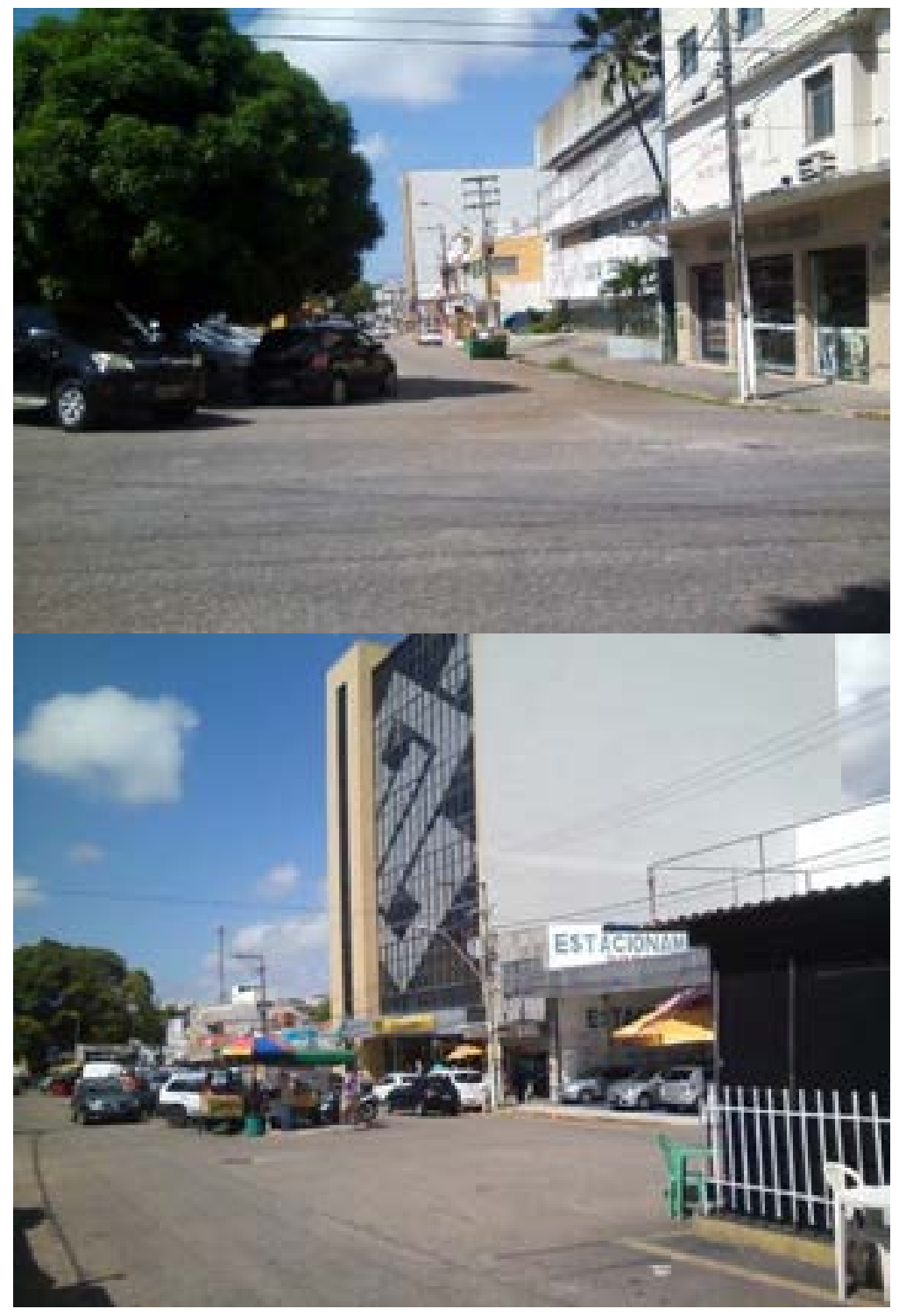

Figura 4 E 5: inicio da Avenida Presidente Bandeira.

Fonte: acervo do autor, 2016. 


\section{Setor Informal: Uma realidade na Avenida Presidente Bandeira no Alecrim}

Por economia informal entendemos as atividades que estão à margem da formalidade, existindo sem firma registrada, sem emitir notas fiscais, sem empregados registrados, sem contribuir com impostos para o governo. Quando os setores primários, secundários ou terciários atuam sem o conhecimento do governo, que não consegue arrecadar impostos e não são recolhidos os encargos sociais dos trabalhadores, estamos diante da economia informal.

São exemplos de atividades mais visíveis na economia informal os vendedores ambulantes que por meio do contrabando vendem suas mercadorias nos grandes centros. No que diz respeito à economia informal na Avenida Presidente Bandeira verificamos que há uma grande presença de vendedores autônomos, camelôs que atuam nos mais variados trechos da avenida ofertando os mais diversos produtos. No próximo capítulo, analisaremos a área de estudo que é a Avenida Presidente Bandeira no bairro do Alecrim.

Assim, esta Avenida se apresenta como um micro espaço onde a divisão do trabalho é caracterizada pela presença do comércio formal e do informal. No comércio formal se apresenta as lojas, muitas tradicionais, que fazem parte da história do bairro estudado, essas lojas dividem o espaço com os comerciantes ambulantes e os camelôs que disputam entre si os transeuntes que por ali passam no fervilhar do cotidiano. Desta forma, este é o atual quadro que encontramos na área escolhida como objeto de nossa análise nesse trabalho.

\section{Considerações Finais}

A Produção/Reprodução do espaço urbano se constitui na base do objeto de estudo da Geografia o qual possibilita a compreensão dialética de como se dá o processo de construção da cidade até os dias atuais, ou seja, sua atual reconfiguração socioespacial. O setor de comércio e serviços é um conceito da Geografia que está ligado ao processo de produção/reprodução do espaço geográfico uma vez que tem influência direta nesse processo, transformando-o de forma substancial.

O setor terciário como também é chamado é uma dos que mais se destaca na economia mundial de países em vias de desenvolvimento, inclusive no Brasil onde tem grande participação no PIB, assim também se verifica que o setor de comercio e serviço tem sua importância na economia potiguar, sobretudo na cidade de Natal a capital do estado onde se concentra o maior fluxo de comércio e serviços.

0 recorte socioespacial desse nosso estudo procurou evidenciar e analisar o setor terciário na Avenida Presidente Bandeira no bairro do Alecrim, zona leste da capital potiguar. Nele vimos que há uma diversidade do setor terciário que transparece no comércio lojista [formal] e o comercio informal [camelôs] além dos serviços das mais diversas áreas, tai como saúde, educação, beleza, alimentação etc.

O setor terciário movimenta segundo a Associação dos Lojistas do bairro do Alecrim cerca de $44 \%$ do ICMS que é arrecadado em impostos pelos órgãos de tributação dos governos estadual e municipal. No entanto, o que é arrecadado pouco ou quase nada retorna em benefícios para os moradores e/ou frequentadores do bairro. É flagrante a falta de estrutura nas grandes vias de circulação têm prejudicado a questão da mobilidade urbana. 
Ainda podemos citar como condicionantes que impedem o funcionamento ideal do bairro do Alecrim a segurança e a falta de estacionamentos entre outros aspectos. Apesar disso verificamos com o estudo que a avenida objeto de nossa investigação se constitui como uma das principais artérias viárias do bairro do Alecrim e responsável por seu dinamismo econômico que transparece na diversidade do setor terciário que nela existe. Assim, acreditamos que alguns problemas deveriam ser resolvidos em comum acordo entre o poder público, os lojistas e comerciantes informais na área em estudo, como por exemplo, adequação do transito para melhorar o fluxo de carros e pedestres, solucionar a questão de estacionamento que é um dos grandes problemas para motoristas que trafegam pelo bairro.

Além disso, acreditamos que adequar ou até mesmo reformular o camelódromo seria uma alternativa para solucionar o entrave entre lojistas e comerciantes informais. Esteticamente e estruturalmente o camelódromo é uma rugosidade visível na paisagem que deixa muito a desejar para a dinâmica estrutural da cidade do Natal. No entanto há que se cobrar algumas iniciativas do poder público que visam melhorar a fluidez do transito como corredor exclusivo para ônibus, ou seja, de políticas públicas urbanas no bairro e, principalmente na avenida Presidente Bandeira, a nosso ver uma boa alternativa para melhorar o trânsito e que deveria se estender em outras áreas do bairro do Alecrim.

\section{Referências}

ALONSO, José Antônio Fialho; BANDEIRA, Pedro Silveira. A desindustrialização de Porto Alegre: causas e perspectivas. Ensaios FEE, Porto Alegre, v. 9, n. 1, p. 3-28. 1988.

Anuário Estatístico do Rio Grande do Norte, 2014, PDF.

BARROS, Sandra Augusta Leão. Que recorte territorial podemos chamar de bairro? 0 caso de Apipucos e poço da panela no Recife. Revista de Urbanismo, Santiago de Chile, n, mar. 2004. Disponível em: http://revistaurbanismo.uchile.cl/. Acesso em: 24/01/2015.

BEZERRA, J. A. A reafirmação do bairro: um estudo geo-histórico do Alecrim na cidade de Natal-RN. Dissertação (Mestrado em Geografia), Universidade Federal do Rio Grande do Norte, Programa de Pós-Graduação em Geografia, Natal, 2005.

CAFEHISTORIA. http://cafehistoria.ning.com/profiles/blogspot.com.

CAERN. Companhia de Águas e Esgotos do Rio Grande do Norte. Disponível em: http:// www.caern.rn.gov.br. http://www.caern.rn.gov.br/

CÂMARA, Anfilóquio. In: Urbanismo. Natal Não-Há-Tal: Aspectos da História da Cidade do Natal/ Secretaria de Meio Ambiente e Urbanismo; organização de João. Gothardo Dantas Emerenciano. Natal: Departamento de Informação, Pesquisa e Estatística, 2007.

CASCUDO, Luiz da Câmara. História da Cidade do Natal. Natal: RN econômico, 2000.

CASTILHO, C. J. M. As Atividades dos serviços, sua história e seu papel na organização do espaço urbano: uma "nova" perspectiva para a análise geográfica? Revista de Geografia, Recife, v. 14, n. 1/2, p. 29-89, jan./dez. 1998.

COMPRENOALECRIM. http://www.comprenoalecrim.com.br.

CORRÊA, H. L.; CAON, M. Gestão de serviços: lucratividade por meio de operações e de satisfação dos clientes. São Paulo: Atlas, 2002. 
CORRÊA, HENRIQUE L. e GIANESI, IRINEU G. N. - "Just In Time, MRP II e OPT: um enfoque estratégico". São Paulo, Atlas, 1993.

CORRÊA, R. L. Área central: mudanças e permanências - uma retrospectiva. In: IX Simpósio Nacional de geografia Urbana. Cidades, territorialidade, sustentabilidade e demandas sociais. Manaus-AM, 18-21 Anais..., out. 2005.

COSERN. Companhia Energética do Rio Grande do Norte. http://www.cosern.com.br/Pages/ default.aspx

DANTAS, Manoel. In: natal daqui a cinquenta anos. Natal Não-Há-Tal: Aspectos da História da Cidade do Natal/ Secretaria de Meio Ambiente e Urbanismo; organização de João. Gothardo Dantas Emerenciano. Natal: Departamento de Informação, Pesquisa e Estatística, 2007.

Dicionário HOUAISS, $1^{\text {a }}$ edição. Rio de Janeiro: Objetiva, 2001.

GALVÃO, Hélio. In: aspectos da evolução urbana e demográfica de natal. Natal Não-HáTal: Aspectos da História da Cidade do Natal/ Secretaria de Meio Ambiente e Urbanismo; organização de João. Gotardo Dantas Emerenciana. Natal: Departamento de Informação, Pesquisa e Estatística, 2007.

FELIPE, José Lacerda Alves et all. Atlas, Rio Grande do Norte: espaço geohistórico e cultural. João Pessoa: Editora Grafset, 2011.

GIL, Antônio Carlos. Métodos e Técnicas de Pesquisa Social. São Paulo; Atlas 2007.

GOMES, R. C. C.; SILVA, A. B.; SILVA, V. P. O Setor Terciário em Natal. In: VALENÇA, M. M.; GOMES, R. C. C. (Org.). Globalização e desigualdade. Natal: A. S. Editores, 2002, p. 289-310.

HARVEY, David. A justiça social e a cidade. São Paulo: Hucitec, 1980.

IBGE-Instituto Brasileiro de Geografia e Estatística.

Contas Regionais do Brasil 2013. http://www.ibge.gov.br/estadosat/temas. php?sigla=rn\&tema=contasregionais2013.

Pesquisa Anual de Comércio, 2013.

Pesquisa Anula de Serviços, 2013.

IDEMA - Instituto de Desenvolvimento Econômico e Meio Ambiente.Perfil do Rio Grande do Norte.Disponivel em PDF.2012.

INFOESCOLA. http://www.infoescola.com/economia/setor-terciario/

Acessoem24/11/2014.

INFOESCOLA. http://www.infoescola.com/sociedade/estudo-de-caso/ - Acesso em 05/12/2014.

JÚNIOR, Manoel Procópio de Moura. In: Presidentes das ruas numeradas do Alecrim. Natal Não-Há-Tal: Aspectos da História da Cidade do Natal/ Secretaria de Meio Ambiente e Urbanismo; organização de João. Gothardo Dantas Emerenciano. Natal: Departamento de Informação, Pesquisa e Estatística, 2007. 
KREIN, José Dari; WEISHAUPT Proni, Marcelo. Economia informal: aspectos conceituais e teóricos / José Dari Krein e Marcelo Weishaupt Proni; Escritório da OIT no Brasil. Brasília: OIT, 2010.

LAKATOS, Eva Maria/ Marconi, Marina de Andrade. Fundamentos de metodologia cientifica. $6^{\mathrm{a}}$ Ed. São Paulo: Editora Atlas, 2007.

LEFEBVRE, Henri. Espaço e política. Belo Horizonte, Editora UFMG, 2008.

MEIRELES, Dilmaria Silva e. In: Conceito de Serviços, sd. Disponível em PDF.

NASCIMENTO, Gerson Gomes do. Shopping-centers: elementos de (re) produção urbana na zona sul de Natal-RN. Dissertação (Mestrado em Geografia) - UFRN, Natal, 2003.

A redefinição do espaço urbano de Natal/RN a partir da influência dos serviços: uma análise das avenidas Bernardo Vieira e Engenheiro Roberto Freire. Tese de Doutorado. Programa de Pós-Graduação em Ciências Sociais da Universidade Federal do Rio Grande do Norte: Natal-RN, 2011.

Os novos caminhos do setor terciário em Natal/RN: uma análise a luz das questões territoriais. Rio Grande do Norte: Temáticas contemporâneas da Reorganização do território. Maria Cristina Cavalcanti Araújo e Valdenido Pedro da Silva [organizadores]. Natal: Editora do CEFET, 2007.

NATAL.http://natal.rn.gov.br/semurb

OMB100. http://www.omb100.com/natal-alecrim/historia.

Perfil do Rio Grande do Norte. Secretaria de Estado do Planejamento e das Finanças. 2013. Consultado em 07 de jun. 2016. (disponível em PDF).

SANTOS, Milton, 1926-2001. A Natureza do Espaço: Técnica e Tempo, Razão e Emoção / Milton Santos. - 4a Ed. 2a . Reimp. São Paulo: Editora da Universidade de São Paulo, 2006.

Espaço e método. São Paulo: Editora da USP, 2008.

Por uma outra globalização. Do pensamento único a consciência universal. $6^{a}$ ed. Rio de Janeiro: Record, 2001.

SECRETARIA MUNICIPAL DE MEIO AMBIENTE E URBANISMO. Conheça melhor seu bairro Alecrim. Natal: Prefeitura Municipal do Natal, 2008.

SUAPESQUISA. http://www.suapesquisa.com/geografia/setores_economia.htm

TRIBUNA DO NORTE. http://tribunadonorte.com.br/noticia/comercio-de-rua-impulsiona-aexpansao-economica-do-rn/280957. Acesso em 19/11/2014.

YIN, R. K. (2005) Estudo de caso: Planejamento e métodos. Porto Alegre: Editora Bookman. 